\title{
Clinical, Endoscopic, Pathological and Serological Findings of Helicobacter pylori Infection in Saudi Patients with Upper Gastrointestinal Diseases
}

\author{
Maha A. Abo-Shadi ${ }^{1 *}$, Tarek A. El-Shazly ${ }^{2}$ and Mariam S. Al-Johani ${ }^{3}$ \\ ${ }^{1}$ Department Microbiology and Immunology, Al-Azhar University, Egypt \\ ${ }^{2}$ Department Internnal Medicine, Mansoura university, Egypt \\ ${ }^{3}$ Department of Biology, Taibah University, KSA.
}

\begin{abstract}
Authors' contributions
This work was carried out in collaboration between all authors. All the authors have made substantial contributions to the intellectual content of the paper. Author MAA planned and designed the study, wrote the protocol, participated in the interpretation of the results and analysis, drafted and critically revised the manuscript for important intellectual content and approval of the version to be published. Author TAE participated in planning and designing the study, sample collection and drafting of the manuscript. Author MSA collected the data and performed the practical laboratory activities. All authors also read and approved the final
\end{abstract} manuscript.

Research Article

Received $26^{\text {th }}$ November 2012 Accepted $17^{\text {th }}$ January 2013 Published 22 ${ }^{\text {nd }}$ March 2013

\section{ABSTRACT}

Background: The prevalence of Helicobacter pylori is typically higher in developing countries like Saudi Arabia.

Aims: To estimate the prevalence of $H$. pylori among patients suffering from upper gastrointestinal (Gl) symptoms, know the main risk factors leading to infection, and detect the clinical, endoscopic and pathological changes of the gastric mucosa of patients infected with $H$. pylori.

Place and Duration of Study: This is a five-months prospective study conducted in King Fahd Hospital, Al-Madinah, Saudi Arabia.

Methodology: $H$. pylori status in patients was determined by two biopsy based tests (histology and rapid urease test) as invasive tests and by a serological testing (ELISA 
$\lg G)$ as non-invasive test.

Results: The age of the selected 68 patients ranged from $18-70$ years with a mean age of $37.9 \pm 14.15$ years. $H$. pylori was more prevalent among males than females $(70.5 \%$ vs $29.5 \%, \mathrm{p}=0.020)$ and among age group $(18-<30)$ years. No significant difference was estimated between positive and negative HP cases in residency, work status, marital status, smoking, socioeconomic level and aspirin intake. The most common complaints in the selected patients having endoscopy were: epigastric pain, heart burn, and dyspepsia. A significant correlation was detected between $\mathrm{H}$. pylori and each of age, sex and Diabetes Mellitus. The most prevalent endoscopic findings of the positive $\mathrm{H}$. pylori cases were mild gastritis (84.1\%). There was a significant difference in gastritis $(\mathrm{p}=0.003)$ and duodenitis $(\mathrm{p}=0.031)$ between positive and negative cases for $\mathrm{H}$. pylori histopathology. The prevalence of $H$. pylori was $60.29 \%$ by rapid urease test, $64.7 \%$ by histopathological examination and $67.6 \%$ by serology among the studied cases.

Conclusion: $H$. pylori-infected patients with upper Gl symptoms were found to have more abnormal endoscopic and pathological findings than those without $H$. pylori infection.

Keywords: Helicobacter pylori; histopathology; serology; lgG; upper gastrointestinal symptoms; endoscopy.

\section{INTRODUCTION}

Helicobacter pylori (HP) are gram negative spiral bacteria that colonize the human stomach [1]. HP is found in half the population of the world. Its prevalence is highly variable in relation to geography, ethnicity, age, and socioeconomic factors [2].

The incidence of HP infection in the developing world is higher than developed countries, and occurs at younger age [2,3]. Infection once established can persist for life if left untreated. Only $30 \%$ of those infected are clinically symptomatic and have active inflammation in the gastric mucosa [4,5]. Infection also can cause chronic gastritis that may lead to gastric atrophy and intestinal metaplasia, peptic ulcer, mucosa-associated lymphoid tissue lymphoma, or adenocarcinoma $[6,7]$.

HP infection has been reported to be hyperendemic in Saudi Arabia and markedly increased with age $[8,9]$.

Several techniques, both invasive and noninvasive, have been developed to diagnose HP infection. Endoscopic diagnostic tests for HP include histological examination of the gastric mucosa, culture of gastric mucosal biopsy cells and the biopsy urease test. However, these procedures are invasive and expensive [10]. Non-invasive testing as serology for HP infection is recommended for dyspeptic patients in primary care, in particular if they are aged $<55$ years and have no alarm symptoms [11].

The association of HP with upper gastrointestinal diseases is widely reported, but it remains unclear whether HP infection actually causes symptoms or is just an associated finding. If HP was significantly associated with upper gastrointestinal diseases and associated symptoms, eradication of the organism could be expected to lead to clinical improvement. Rapid and correct diagnosis of HP is thus critical for treatment and to prevent potential complications. 
The study was conducted to estimate the prevalence of HP among patients suffering from upper gastrointestinal (Gl) symptoms in King Fahd hospital, know the main risk factors leading to infection, and detect the clinical, endoscopic and pathological changes of the gastric mucosa of HP infected patients.

\section{MATERIALS AND METHODS}

\subsection{Study Location and Patients}

This five-months prospective study was conducted in King Fahd Hospital, Al-Madinah, Saudi Arabia, in the period between 1, March to 30, July, 2011.

All the patients were subjected to a questionnaire to collect some Socio-Demographic data (age, gender, weight, height, marital, status, highest educational level and occupation), current complaint and medical history.

Education, income, and occupational status were the most commonly used variables to measure Socioeconomic Status (SES). Each SES measure had its own strengths and limitations when the relationship between SES and health outcomes was studied. Many researchers suggested that education is the most stable and robust indicator of SES. Thus, we selected education level of the subjects as the primary measure of SES similar to Zhang and Wang [12]. Education is more comparable across time than income or occupation; and had little missing data, compared with income. We coded the education level as follows: low education (less than high school, meaning ninth grade or less), medium education (high school, meaning $10^{\text {th }}$ to $12^{\text {th }}$ grades), and high education (college or higher) to indicate low, medium, and high SES.

Patients were excluded according to criteria designed by Westbrook et al. [13] if they (1) were inpatients, (2) did not have one or more of 10 upper Gl symptoms (epigastric pain, vomiting, nausea, heartburn, acid regurgitation, anorexia, early satiety, dysphagia, bloating or moderate to severe burping/belching), (3) had a Gl bleed, (4) had a previous history of peptic ulcer disease or cancer, (5) had undergone a previous endoscopy or gastric surgery, (6) under 16 years of age, (7) experienced a developmental disability or (8) had gallstones.

In addition to the above exclusion criteria, those who had received a previous antihelicobacter therapy, non-steroidal anti-inflammatory drugs or anti-secretory drugs (including $\mathrm{H}_{2}$-receptor antagonists or proton pump inhibitors) in the preceding 4 weeks, were also excluded.

This study thus excluded many patients after clinical examination, leaving a sample of 68 patients (41 males and 27 females). Their Nationalities were different (52 Saudi, 2 Egyptian, 4 Yemeni, 5 Pakistani, 1 Lebanese, 1 Syrian, 1 Jordanian, 1 Omani and 1 Indian). Fifteen healthy population (10 males and 5 females) were also included in this study to detect $H$. pylori lgG among them.

\subsection{Collection of Samples and HP Screening Tests}

Upper gastrointestinal endoscopy was performed to all the selected cases by the second author at the endoscopy unit, King Fahd Hospital using an Olympus, GIF-SP 240 
Gastroscope. For all cases, a total of three biopsy specimens were taken from the antral mucosa.

HP status in patients was determined by two biopsy based tests (histology and rapid urease test) as invasive tests and by a serological testing (ELISA IgG) as non-invasive test.

A rapid urease test (CLO test, Ballard Medical Products, UTAH, USA) was performed on the first antral biopsy. The gastric biopsy specimen was immediately embedded into the gel in the kit. The kit was placed in the room temperature for $24 \mathrm{~h}$. The test was considered positive if the color changed into red or magenta. The remaining specimens were sent for histopathological evaluation.

Immediately after collection, gastric biopsy specimens were fixed in 10\% buffered formaldehyde and embedded in paraffin for sectioning using automated tissue processor (Thermo Scientific, Germany). The slides were stained by hematoxylin and eosin stain, using auto stainer (Thermo Scientific, Germany). The slide of biopsy specimen was then examined for the presence of inflammation, HP, atrophy, and intestinal metaplasia.

Serological detection of HP in serum of patients and healthy population was done by measuring anti-H. pylori lgG antibodies using Enzywell $H$. pylori lgG kits (Diesse diagnostic senese-Italy Diesse).

\subsection{Statistical Analysis}

Statistical analysis was performed using Statistical Package for Social Sciences SPSS (version 13). Frequencies, percentages and arithmetic mean were calculated. Chi-square test (with Yates Correction) and t-test were used accordingly. Bivariate correlation (spearman Correlation) was used. P value $<0.05$ was considered significant.

\section{RESULTS}

Socio-Demographic description of the studied patients are presented in Table 1. Their ages ranged from 18 to 70 years with a mean of $37.9 \pm 14.15$ years. The age groups were as the following: (18 - < 30 years, 47.7\%), (30 - < 45 years, 20.5\%), (45 - 60 years, 27.3\%) and (> 60 years, $4.5 \%)$ with no significant difference among them $(\mathrm{p}=0.172)$. In addition, Males had higher HP positivity (31 cases, $70.5 \%$ ) than females (13, 29.5\%). 
Table 1. Socio-demographic description of the studied patients

\begin{tabular}{|c|c|c|c|c|c|c|c|}
\hline & \multicolumn{2}{|c|}{$\begin{array}{l}\text { Negative } \\
\text { histopathology } \\
\text { for HP }\end{array}$} & \multicolumn{2}{|c|}{$\begin{array}{l}\text { Positive } \\
\text { histopathology } \\
\text { for HP }\end{array}$} & \multicolumn{2}{|c|}{ Total } & \multirow[t]{2}{*}{$\begin{array}{l}\text { Test of } \\
\text { significance } \\
\text { p-value }\end{array}$} \\
\hline & $\mathrm{N}=24$ & $\%$ & $\mathrm{~N}=44$ & $\%$ & $\mathrm{~N}=6 \varepsilon$ & $\%$ & \\
\hline \multicolumn{8}{|l|}{ Age in years } \\
\hline $\begin{array}{l}\text { Mean } \pm \text { SD } \\
\text { Sex }\end{array}$ & \multicolumn{2}{|c|}{$42.8 \pm 14.97$} & \multicolumn{2}{|c|}{$35.2 \pm 13.10$} & \multicolumn{2}{|c|}{$37.9 \pm 14.15$} & $0.034^{*}$ \\
\hline Female & 14 & 58.3 & 13 & 29.5 & 27 & 39.7 & $0.020^{*}$ \\
\hline Male & 10 & 41.7 & 31 & 70.5 & 41 & 60.3 & \\
\hline \multicolumn{8}{|l|}{ Nationality } \\
\hline Saudi & 16 & 66.7 & 36 & 81.8 & 52 & 76.5 & 0.159 \\
\hline Non Saudi & 8 & 33.3 & 8 & 18.2 & 16 & 23.5 & \\
\hline \multicolumn{8}{|l|}{ Residence } \\
\hline Outside Medinah & 4 & 16.7 & 2 & 4.5 & 6 & 8.8 & 0.092 \\
\hline Medinah City & 20 & 83.3 & 42 & 95.5 & 62 & 91.2 & \\
\hline \multicolumn{8}{|l|}{ Work status } \\
\hline Non working & 13 & 54.2 & 16 & 36.4 & 29 & 42.6 & 0.156 \\
\hline Working & 11 & 45.8 & 28 & 63.6 & 39 & 57.4 & \\
\hline \multicolumn{8}{|l|}{$\begin{array}{l}\text { Current marital } \\
\text { status }\end{array}$} \\
\hline Single & 5 & 20.8 & 16 & 36.4 & 21 & 30.9 & 0.185 \\
\hline Married & 19 & 79.2 & 28 & 63.6 & 47 & 69.1 & \\
\hline \multicolumn{8}{|l|}{ Active smoking } \\
\hline Non smoker & 18 & 75.0 & 36 & 81.8 & 54 & 79.4 & 0.506 \\
\hline Smoker & 6 & 25.0 & 8 & 18.2 & 14 & 20.6 & \\
\hline \multicolumn{8}{|l|}{$\begin{array}{l}\text { Socioeconomic } \\
\text { level }\end{array}$} \\
\hline Low & 4 & 16.7 & 3 & 6.8 & 7 & 10.3 & 0.202 \\
\hline Medium \& high & 20 & 83.3 & 41 & 93.2 & 61 & 89.7 & \\
\hline
\end{tabular}

The most common complaints among the studied patients were: epigastric pain (61 cases, $89.7 \%$ ), heart burn (46 cases, 67.6\%), dyspepsia (45 cases, 66.2\%), diarrhea (12 cases, $17.6 \%)$ (Not presented in a Table).

There was a significant difference in age, sex dyspepsia, diarrhea and Diabetes Mellitus (DM) between positive and negative HP cases $(p=0.034, p=0.020, p=0.027, p=0.012$ and $\mathrm{p}=0.026$, respectively).

Interestingly, all DM cases $(8 / 8,100 \%)$ in our setting had HP, while only $60 \%$ of the non diabetic patients $(36 / 60)$ had HP.

Regarding associated medical conditions of the studied cases (Not presented in a table), 8 cases $(11.8 \%)$ had DM, while 10 cases $(14.7 \%)$ had hypertension. Most of our patients were non hypertensive and $67.2 \%(39 / 58)$ of them had HP while only $50 \%$ of hypertensive patients $(5 / 10)$ had HP.

Diastolic blood pressure was higher in HP positive cases $(94.5 \pm 17.62)$ than negative cases (76.4 \pm 7.53$)$ but with no significant difference $(p=0.061)$. On the other hand, there was a 
significant difference $(p=0.000)$ in the pulse rate between positive HP cases $(80.4 \pm 13.15)$ and negative cases $(80.5 \pm 9.00)$. Box blots for blood pressure and pulse rate for positive and negative HP cases are drawn in Figs. 1 and 2, respectively.

Endoscopic findings of our patients (Table 2), revealed that positive HP cases had mild gastritis in $84.1 \%$ of them, severe gastritis in $15.9 \%$, duodenitis in $11.4 \%$ and reflux oesphagitis in $6.8 \%$. In addition, there was a significant difference in gastritis $(p=0.003)$ and duodenitis $(p=0.031)$ between positive and negative cases for HP histopathology. Normal duodenum was present in $88.6 \%$ of positive HP cases, while there was no patient with normal gastric mucosa among them.

Table 2. Endoscopic, histopathological and HP serological findings of the studied patients

\begin{tabular}{|c|c|c|c|c|c|c|c|}
\hline & \multicolumn{2}{|c|}{$\begin{array}{l}\text { Negative } \\
\text { histopathology } \\
\text { for HP }\end{array}$} & \multicolumn{2}{|c|}{$\begin{array}{l}\text { Positive } \\
\text { histopathology } \\
\text { for HP }\end{array}$} & \multicolumn{2}{|l|}{ Total } & \multirow[t]{2}{*}{$\begin{array}{l}\text { Test of } \\
\text { significance } \\
\text { p-value }\end{array}$} \\
\hline & $\mathrm{N}=24$ & $\%$ & $\mathrm{~N}=44$ & $\%$ & $\mathrm{~N}=68$ & $\%$ & \\
\hline \multicolumn{8}{|c|}{$\begin{array}{l}\text { Endoscopic findings } \\
\text { Reflux oesphagitis }\end{array}$} \\
\hline No & 24 & 100.0 & 41 & 93.2 & 65 & 95.6 & 0.191 \\
\hline Yes & 0 & 0.0 & 3 & 6.8 & 3 & 4.4 & \\
\hline \multicolumn{8}{|l|}{ Gastritis } \\
\hline Normal & 5 & 20.8 & 0 & 0.0 & 5 & 7.4 & \\
\hline Mild & 12 & 50.0 & 37 & 84.1 & 49 & 72.1 & $0.003^{*}$ \\
\hline Moderate & 1 & 4.2 & 0 & 0.0 & 1 & 1.5 & \\
\hline Severe & 6 & 25.0 & 7 & 15.9 & 13 & 19 & \\
\hline \multicolumn{8}{|c|}{ Duodenitis } \\
\hline Normal & 17 & 70.8 & 39 & 88.6 & 56 & 82.4 & \\
\hline Mild & 7 & 29.2 & 3 & 6.8 & 10 & 14.7 & $0.031^{*}$ \\
\hline Severe & 0 & 0.0 & 2 & 4.6 & 2 & 2.9 & \\
\hline \multicolumn{8}{|c|}{$\begin{array}{l}\text { Histopathological and } \\
\text { HP serological data } \\
\text { Gastritis }\end{array}$} \\
\hline Mild & 17 & 70.8 & 25 & 56.8 & 42 & 61.8 & \\
\hline Moderate & 5 & 20.8 & 7 & 15.9 & 12 & 17.6 & $0.027^{*}$ \\
\hline Severe & 0 & 0.0 & 10 & 22.7 & 10 & 14.7 & \\
\hline Atrophic & 0 & 0.0 & 2 & 4.5 & 2 & 2.9 & \\
\hline $\begin{array}{l}\text { Specific } \\
\text { Metaplas }\end{array}$ & 2 & 8.3 & 0 & 0.0 & 2 & 2.9 & \\
\hline Absent & 23 & 95.8 & 44 & 100.0 & 67 & 98.5 & 0.173 \\
\hline $\begin{array}{l}\text { Present } \\
\text { lgG }\end{array}$ & 1 & 4.2 & 0 & 0.0 & 1 & 1.5 & \\
\hline Negative & 5 & 20.8 & 17 & 38.6 & 22 & 32.4 & 0.134 \\
\hline Positive & 19 & 79.2 & 27 & 61.4 & 46 & 67.6 & \\
\hline
\end{tabular}




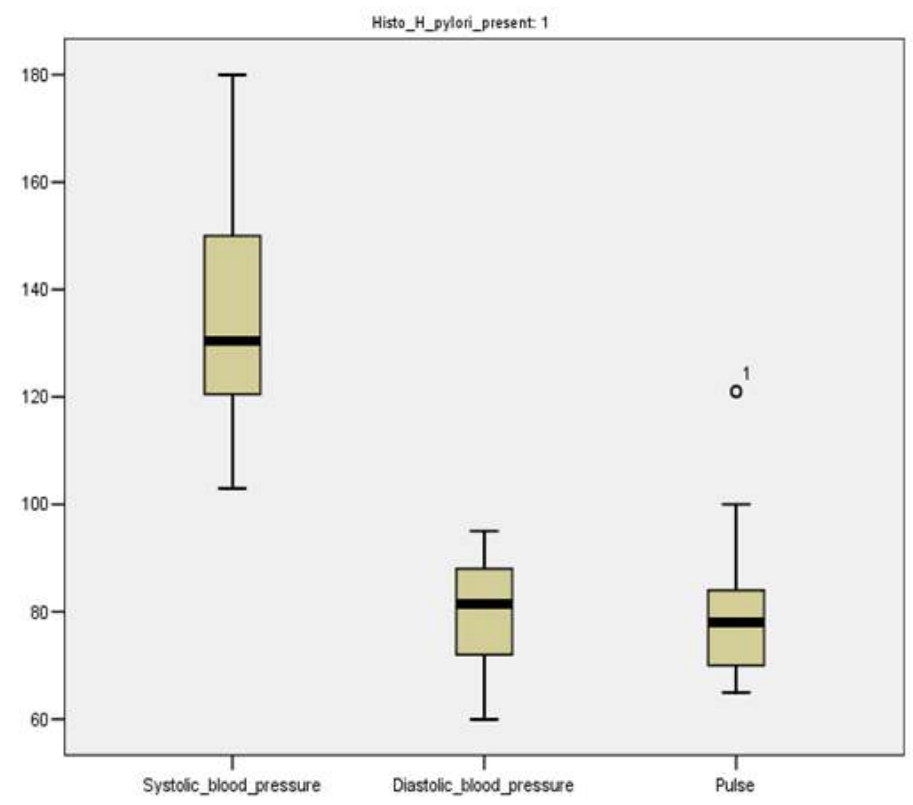

Fig. 1. Box blot for blood pressure and pulse rate for positive HP cases

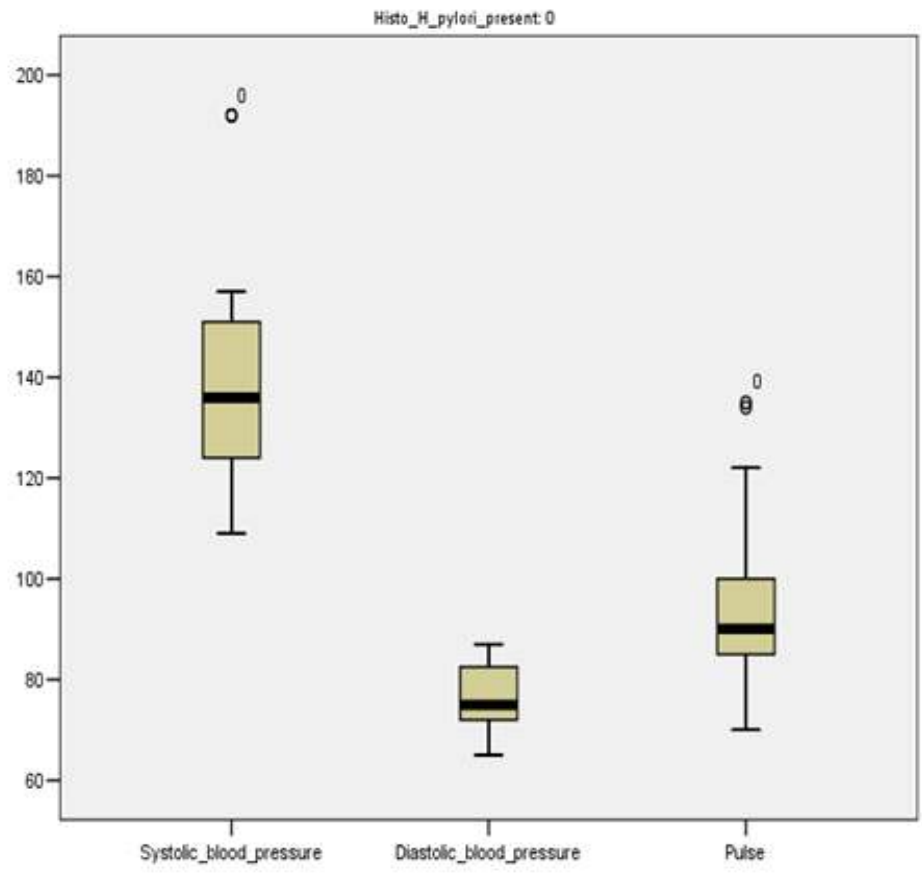

Fig. 2. Box blot for blood pressure and pulse rate for negative HP cases

Histopathological and serological findings of the studied patients are presented in Table 2. There was a significant difference in gastritis between positive and negative HP cases. The cases with the highest frequency being associated with mild gastritis. 
None of our patients had dysplasia. All cases positive for HP were metaplasia and neoplasia negative. H. pylori IgG was positive in $61.4 \%$ of HP positive histopathology cases.

Data revealed the prevalence of HP in $64.7 \%$ (44/68 cases) of all studied patients histologically, $60.29 \%(41 / 68)$ by CLO and in $67.6 \%$ (46/68 cases) by serology.

The incidence of $H$. pylori IgG among healthy population was found to be $73.3 \%(11 / 15$ cases), but without confirmation of HP presence as endoscopy could not be done for them. Fig. 3 is photomicrograph of gastric biopsy specimen from one clinical case.

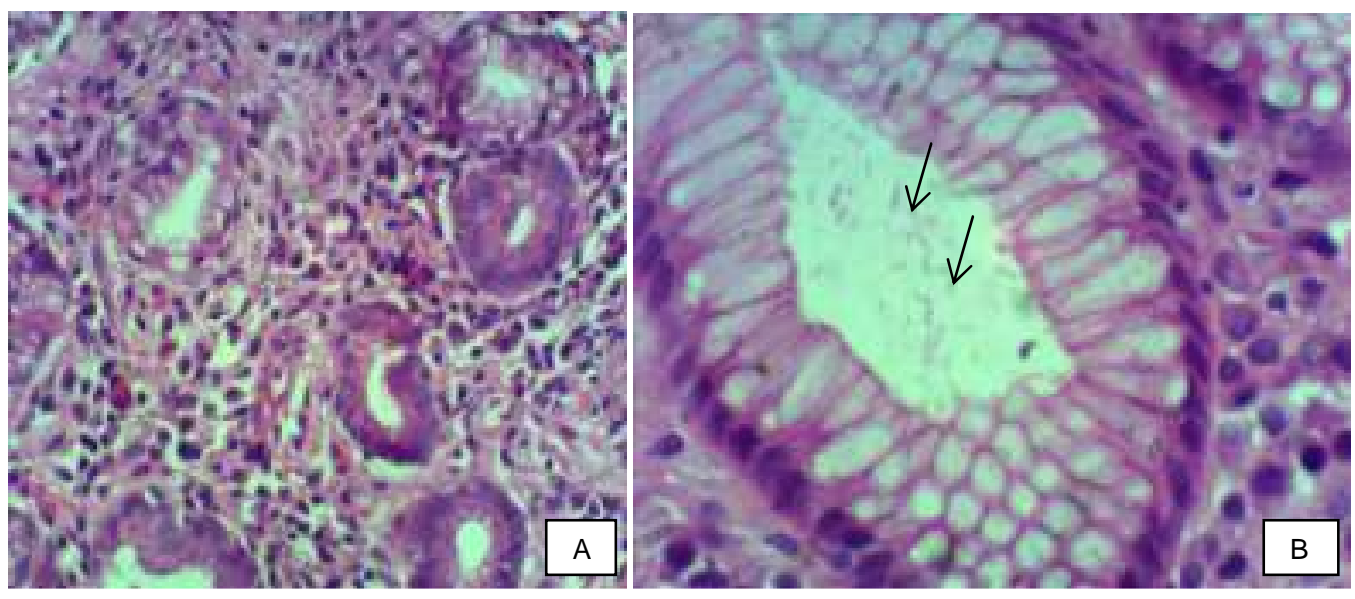

Fig. 3. Photomicrograph of gastric biopsy specimen of the antrum from patient no 36 (A) Moderate active gastritis, with no intestinal metaplasia or neoplasia. (B) Enlarged photomicrograph A, the arrows are pointing to HP.

All patients positive for HP were treated for 2 weeks with the triple therapy using a proton pump inhibitor (PPI) (esomeprazole $20 \mathrm{mg}$ twice daily), amoxicillin (1 $\mathrm{g}$ twice daily), and clarithromycin (500 mg twice daily).

Only 40 patients were seen at follow up after 2 weeks. All but five reported improvement in their presenting symptoms during their follow up visits. The other five patients continued to have abdominal pain in spite of good compliance with the treatment and were subjected for further evaluation.

\subsection{Discussion}

Histological study is still considered by many to be the "gold standard" for HP diagnosis. Not only does it reliably identify infection, but it also can provide information on underlying gastric pathology [14]. We had three biopsies from each case because HP is not evenly distributed throughout the gastric mucosa, and, at least two biopsies need to be performed to sensitively diagnose infection [15]. A significant correlation between age and HP ( $r=0.257$, $p=0.034$ ) was detected in this setting, whereas other studies $[16,17]$ found no significant correlation between HP infection and age.

In the present study, HP incidence was much higher (47.7\%) in the younger age group (18 $<30$ years) meaning that it is acquired in a younger age. This is in accordance to the result 
of Iman et al. [18] who reported a much higher incidence below 40 years than above 40 years. Morad et al. [19] revealed high frequencies of HP infection during the second, third, and fourth decades of life. Bakka et al. [20] detected the prevalence of $H$. pylori of $82 \%$ among patients $<45$. On the other hand, Akbar and Eltahawy [16] observed a higher prevalence of positive HP infection (71\%) among individuals between 35-75 years of age, when compared with frequency in other age groups.

HP was detected in $64.7 \%$ of gastric biopsies from our 68 patients with upper Gl symptoms. Different HP detection rates in gastric biopsies (54.9\%, [21]; 65\%, [18]; 73.98\%, [22]; 75.4\%, [23]) were previously reported.

In the present work, $H$. pylori was significantly more prevalent in males than females regarding histopathology (Table 1 ). Several studies also reported that males were affected more than females [24-27]. Furthermore, de Martel and Parsonnet [28] showed a significant and homogeneous elevated risk of infection among adult men concordant with their elevated risk for HP related diseases.

Other studies reported a higher HP prevalence in females than males [16,18,29]; while no gender-related significant difference in the prevalence of HP infection in another studies $[8,17,19,30-32]$.

HP infection among Saudi patients (36/52 cases, 69\%) was found to be higher than nonSaudi (8/16 cases, $50 \%$ ) similar to Morad et al. [19]. On the other hand, Akbar and Eltahawy [16] reported a significantly higher HP prevalence in the non-Saudi patients.

The prevalence of HP infection varies among countries and within a country [33]. The risk factors of HP infection confirmed that low socioeconomic status, crowded living conditions in childhood, low educational level of parents and unreliable well-water supply in the childhood household are associated with the infection [34].

In this work, there was no significant correlation detected between socioeconomic level and HP infection. This could be attributed to a higher admission rate of patients of medium socioeconomic level (89.7\%).

Regarding other risk factors (Table 1), no significant difference was estimated between positive and negative HP cases in residency, work status, marital status, smoking, socioeconomic level and aspirin intake $(p=0.09, p=0.15, p=0.18, p=0.5, p=0.20$ and $p=0.88$ respectively). In accordance, Bakka et al. [20] observed no significant difference in the prevalence of HP among patients and marital status, residency and smoking.

A significant difference in DM between positive and negative HP cases $(p=0.026)$ have been detected in this work.

The relationship between DM and HP infection is controversial. According to some studies, there is a high prevalence of HP infection in patients with either Type 1 or Type 2 DM which is correlated with the duration of DM, the presence of dyspeptic symptoms, cardiovascular autonomic neuropathy, age, gender, BMI, blood pressure, fasting glucose, and the glycated hemoglobin levels. In contrast, other studies showed that HP infection is not associated with $\mathrm{DM}$, as the microvascular changes in the gastric mucosa may create an unfavorable environment for the establishment or survival of HP [35-40]. 
The clinical significance of HP in upper GIT disorders has been confirmed [41,42]. Salih et al. [43] reported a high HP density and the associated genotypes affect the severity of the gastric histology and the disease outcome; and that eradication of HP resulted in a histological improvement of the gastric mucosa. Moreover, Lawal et al. [29] and Kandulski et al. [44] suggested the possible role of the HP infection in dyspeptic conditions.

HP prevalence among the selected dyspeptic patients was $55.6 \%$; which is comparable to Akbar and Eltahawy [16].

HP seems to be a health problem in the neighboring regions of Saudi Arabia. The prevalence of HP among dyspeptic patients differs among different countries. For instance, $86 \%$ in Jordan [45]; between $81 \%$ and $96.6 \%$ in Kuwait [46,47] and $82.2 \%$ in Yemen [48].

Difference in HP prevalence among dyspeptic patients was also observed among other countries. It ranged from 33\%-95\% [49-56].

$90.9 \%$ of the studied cases were suffering from epigastric pain. HP infection was more common $(71.4 \%)$ in patients suffering from epigastric pain [9,57]. Saadah [57]) added that the presence of epigastric pain, especially if associated with dyspeptic symptoms is more associated with abnormal gastric pathology.

Antral mucosa is the main target for HP colonization [58]. Regarding endoscopic finding, HP infection was present in $64.7 \%$ among gastritis and $7.3 \%$ among duodenitis. The frequency of HP infection among those with endoscopic diagnosis of gastritis ranged from $60-80 \%$ $[21,29,50,56,59-61]$.

Gastritis occurs due to the inflammation of the gastric mucosa that can be caused by HP $[62,63]$. Blaser [64] reported that chronic active gastritis is mainly induced by HP. We have discovered a significant difference $(p=0.027)$ between positive HP histopathology and grading of gastritis was discovered similar to Akbar and Eltahawy [16]. In healthy population, HP seroprevalence ranges from $25 \%$ in developed countries up to $80 \%$ in developing countries [65]. In this setting, it was $73.3 \%$. This result is comparable to an earlier study by Al-Moagel et al. [8], while lower than study of Khan and Ghazi [66]. Other studies from Libya [20], Nigeria [67], Tunis [68] and Egypt [69] detected anti-H. pylori antibodies in 76\%, 80\%, $83 \%$ and $87.6 \%$ of asymptomatic subjects, respectively. We must mention that our small control number (15 healthy population) should be reported as a limitation in this study. In addition, the HP seroprevalence among those individuals was mostly an indication of past HP exposure not an active infection.

Various diagnostic tests for HP infection may have false negative results, and the use of multiple tests may help to provide a more accurate diagnosis of HP infection [70]. That is the reason for using three different diagnostic HP tests. The prevalence of HP in patients included in the present study was $64.7 \%$ by histology and $67.6 \%$ by serology. Similarly, Marie [9] reported a prevalence of $67 \%$ by serology $H$. pylori IgG among outpatients suffering from GIT symptoms. In addition, Akbar and Eltahawy [16] detected HP in $70 \%$ by histology and $78 \%$ by ELISA.

A negative HP serology test whereas biopsy sampling is simultaneously positive, may be due to the presence of a recent infection; or the presence of IgA against helicobacter instead of IgG in $2 \%$ of total cases [71]. A positive HP serology test whereas biopsy sampling is simultaneously negative, may be due to incorrect sampling from gastric mucosal tissue 
during endoscopy procedure which can decrease the rate of HP identification and isolation [72].

In our setting, sensitivity of IgG was only $61.4 \%$ compared to the histopathology. Monteiro et al. [73] found no statistically significant difference between the invasive tests and the noninvasive tests in the diagnosis of HP infection. Laheij and his associates [74] also reported similar sensitivity and specificity ELISA results compared to the biopsy-based tests in detecting HP infection in dyspeptic patients. This discrepancy may be due to antigens used in the ELISA kits. the sensitivity and specificity of an assay in a particular population may not necessarily be applied to another [72].

In western countries, ELISA kits have been shown to have high sensitivities and specificities $(80-95 \%)$ [75], whereas in developing countries, commercial ELISA kits have low specificities [76-78]. Individuals vary considerably in their antibody responses to HP antigens, and no single antigen is recognizied by sera from all subjects. The accuracy of serological tests therefore depends on the antigens used in the tests making it essential that HP ELISA is locally validated [16].

The vast molecular heterogeneity among HP strains isolated from different geographic regions worldwide necessitates the use of native antigens for such serological assays to avoid false results $[79,80]$.

A significant molecular heterogeneity is existing among Iranian and western HP strains in some bacterial conserved and nonconserved genes was reported [81,82]. Similarly, in Saudi Arabia, the molecular heterogeneity existing between Saudi and non-Saudi and may be between Saudi themselves. This emphasizes the need for use of native (local) antigens in developing ELISA assay for detecting seroreactivity toward this bacteria. Perez-Perez et al. [76] and Bodhidatta et al. [83] reported a higher sensitivity and specificity when using the antigen prepared from local HP isolates than the commercial ELISA re-agent kits. Talebkhan et al. [72] suggested that the cut off values of the imported kits should be refined for user country due to differences in the vast geographic heterogeneity among HP antigens, in order to obtain the highest sensitivity and specificity. Furthermore, they concluded that home made ELISA kit can be substituted for imported ELISA kits due to its valid serological criteria.

\section{CONCLUSION}

In the present study, HP-infected patients with upper Gl symptoms had more abnormal endoscopic and pathological findings than those without HP infection, which might be related to gastric mucosal inflammation.

The lower sensitivity and specificity of $H$. pylori IgG ELISA compared to histopathology after endoscopy, emphasizes the need to locally consider another non-invasive test as urea breath test, immunoblot or antigen stool detection. The non invasive nature of HP lgG ELISA, practicality, low cost and easy applications, are critical characteristics of it making it more accepted than other approaches among clinicians and laboratory staff. This pushes us to recommend shifting to home made ELISA kit to substitute the imported ELISA kits in order to obtain the highest sensitivity and specificity. 


\section{CONSENT}

Written informed consent was obtained from the patients before entering the study.

\section{ETHICAL APPROVAL}

Ethical committee of the king Fahd hospital and the scientific committee of Taibah University approved the study.

\section{COMPETING INTERESTS}

Authors have declared that no competing interests exist.

\section{REFERENCES}

1. Buta N, Tanih NF, Ndip RN. Increasing trend of metronidazole resistance in the treatment of Helicobacter pylori infection: A global challenge. Afric $\mathrm{J}$ Biotechnol. 2010;9(8):1115-1121.

2. World Gastroenterology Organisation. World gastroenterology organisation global guidelines H. pylori in developing countries. J Dig Dis. 2011;12:319-326.

3. Atherton JC. The pathogenesis of Helicobacter pylori-induced gastro-duodenal diseases. Annu Rev Pathol. 2006;1:63-96.

4. Blaser MJ, Atherton JCJ. H. pylori persistence: Biology and disease. J Clin Invest. 2004;113:321-333.

5. Kusters JG, van Vliet $A H$, Kuipers EJ. Pathogenesis of $H$. pylori infection. Clin Microbiol Rev. 2006;19:449-490.

6. Peek RM, Blaser MJ. H. pylori and gastrointestinal tract adenocarcinomas. Nat Rev Cancer. 2002;2(1):28-37.

7. Zhang C, Yamada N, Wu YL, Wen M, Matsuhisa T, Matsukura N. H. pylori infection, glandular atrophy and intestinal metaplasia in superficial gastritis, gastric erosion, erosive gastritis, gastric ulcer and early gastric cancer. World J Gastroenterol. 2005;11(6):791-796.

8. Al-Moagel MA, Evans DG, Abdulghani ME, Adam E, Evans DJJr, Malaty HM, Graham DY. Prevalence of Helicobacter (formerly Campylobacter) pylori infection in Saudi Arabia, and comparison of those with and without upper gastrointestinal symptoms. Am J Gastroenterol. 1990;85(8):944-948.

9. Marie MA. Seroprevalence of $H$. pylori infection in large series of patients in an Urban Area of Saudi Arabia. Korean J Gastroenterol. 2008;52:226-229.

10. vanZwet AA, Thijs JC, Roosendaal R, Kuipers EJ, Peña S, de Graaff J. Practical diagnosis of $H$. pylori infection. Eur J Gastroenterol Hepatol. 1996;8(5):501-507.

11. McColl KE, Murray LS, Gillen D, Walker A, Wirz A, Fletcher J, et al. Randomised trial of endoscopy with testing for $H$. pylori compared with non-invasive, $H$. pylori testing alone in the management of dyspepsia. BMJ. 2002;324:999-1002.

12. Zhang $Q$, Wang $Y$. Trends in the Association between Obesity and Socioeconomic Status in U.S. Adults: 1971 to 2000. Obesity Res. 2012;12(10):1622-1632.

13. Westbrook JI, Duggan AE, Duggan JM, Westbrook MT. A 9 year prospective cohort study of endoscoped patients with upper gastrointestinal symptoms. European $\mathrm{J}$ Epidemiol. 2005;20:619-627. 
14. Perry S, de Martel C, Parsonnet J. H. pylori. In: Evans, A. S. and Brachman, P. S. (eds.). Bacterial infections of humans. pp. 369-394. Springer Science and Business Media, LLC; 2009.

15. Nedenskov-Sorensen P, Aase S, Bjormeklett A, Fausa O, Bukholm G. Sampling efficiency in the diagnosis of $H$. pylori infection and chronic active gastritis. J Clin Microbiol. 1991;29:672-675.

16. Akbar DH, Eltahawy ATA. H. pylori infection at a university hospital in Saudi Arabia: prevalence, comparison of diagnostic modalities and endoscopic findings. Indian J pathol Microbiol. 2005;48(2):181-185.

17. Petrović $M$, Artiko $V$, Novosel $V$, Ille $T$, Šobić-Šaranović $D$, Pavlović $S$, et al. Relationship between $H$. pylori infection estimated by 14C-urea breath test and gender, blood groups and Rhesus factor. Hell J Nucl Med. 2011;14(1):21-24.

18. Iman $\mathrm{N}$, Khan $\mathrm{H}$, Iqbal S, Rehman S. Frequency of $H$. pylori in patients with upper $\mathrm{G}$.I symptoms. J Med Sci. 2008;16(1):1-3.

19. Morad NA, Ahmed ME, Al-Wabel A, Foli AK. H. pylori associated dyspepsia in 208 patients from southern Saudi Arabia. Ann Saudi med. 1993;13:304-313.

20. Bakka AS, El-Gariani AB, AbouGhrara FM, Salih BA. Frequency of $H$. pylori infection in dyspeptic patients in Libya. Saudi Med J. 2002; 23(10):1261-1265.

21. Ayoola AE, Ageely HM, Gadour, MO, Pathak VP. Prevalence of $H$. pylori infection among patients with dyspepsia in South-Western Saudi Arabia. Saudi Med J. 2004;25(10):1433-1438.

22. Mohamed AE, AL Karawi A, AL Jumah A, Ahmed AM, Sharing S, Yasawy MI. $H$. pylori: incidence and comparison of three diagnostic methods in 196 Saudi patients with dyspepsia. Hepatogastroenterol. 1994;41:48-50.

23. Baako BN, Darko R. Incidence of $H$. pylori infection in Ghanaian patients with dyspeptic symptoms referred for upper gastrointestinal endoscopy. West Afr J Med. 1996;15(4):223-227.

24. Shennak MM, Kilani AF. H. pylori in dyspeptic Jordanian patients. Trop Gastroenterol. 1998;19:15-18.

25. $\mathrm{Vu} \mathrm{Y}, \mathrm{Ng} \mathrm{Y}$. Prevalence of $H$. pylori in peptic ulcer disease in a Singapore Hospital. Singapore Med J. 2000;41:478-481.

26. Feinstein LB, Holman RC, Yorita Christensen KL, Steiner CA, Swerdlow DL. Trend in hospitalizations for peptic ulcer disease, United States, 1998- 2005. Emerg Infect Dis. 2010;16(9):1410-1418.

27. Sasidharan S, Uyub AM, Azlan AA. Further evidence of ethnic and gender differences for $H$. pylori infection among endoscoped patients. Asian Pacific J Tropical Dis. 2012;55-59.

28. de Martel C, Parsonnet J. H. pylori infection and gender: a meta-analysis of population-based prevalence surveys. Digest Dis Sci. 2006;51(12):2292-2301.

29. Lawal OO, Rotimi O, Okeke L. H. pylori in Gastroduodenal Diseases. J Nat Med Associ. 2007;99(1):1-4.

30. Blaser MJ. Epidemiology and pathophysiology of Campylobacter pylori infections. Rev Infect Dis. 1990;12(1):99-106.

31. Moges F, Kassu A, Mengistu G, Adugna S, Andualem B, Nishikawa T, et al. Seroprevalence of $H$. pylori in dyspeptic patients and its relationship with HIV infection, ABO blood groups and life style in a university hospital, Northwest Ethiopia. World $\mathrm{J}$ Gastroenterol. 2006;12:1957-1961.

32. Hussein NR. H. pylori and gastric cancer in the Middle East: a new enigma? World $\mathrm{J}$ Gastroenterol. 2010;16(26):3226-3234.

33. Gonzaga L, Coelho V, Leon-Barua R, Quigley EMM. Latin-American consensus conference on H. pylori infection. Amer J Gastroenterol. 2000;95:2688-2691. 
34. Salomaa-Räsänen A, Kosunen TU, Aromaa ARJ, Knekt P, Sarna S, Rautelin H. A "Screen-and-Treat" approach for $H$. pylori infection: A population-based study in Vammala, Finland. Helicobacter. 2010;15:28-37.

35. Perdichizzi G, Bottari M, Pallio S, Fera MT, Carbone M, Barresi G. Gastric infection by Helicobacter pylori and antral gastritis in hyperglycemic obese and in diabetic subjects. New Microbiol. 1996;19:149-54.

36. Arslan D, Kendirci M, Kurtuglou S, Kula M. Helicobacter pylori infection in children with insulin dependent diabetes mellitus. J Peadiatr Endocrinol Metabolism. 2000;13:553-6.

37. Senturk O, Canturk Z, Centinarslan B, Ercin C, Hulagu S, Canturk NZ. Prevalence and comparisons of five different diagnostic methods for Helicobacter pylori in diabetic patients. Endocrin Res. 2001;27:179-89.

38. Quatrini M, Boarino V, Ghidoni A, Baldassarri AR, Bianchi PA, Bardella MT. Helicobacter pylori prevalence in patients with diabetes and its relationship to dyspeptic symptoms. J Clin Gastroenterol. 2001;32:215-7.

39. Bener A, Micallef $R$, Afifi M, Derbala M, Al-Mulla HM, Usmani MA. Association between Type 2 diabetes mellitus and Helicobacter pylori infection. Turk $\mathrm{J}$ Gastroenterol. 2007;18:225-9.

40. Demir M, Gokturk HS, Ozturk NA, Kulaksizoglu M, Serin E, Yilmaz U. Helicobacter pylori prevalence in diabetes mellitus patients with dyspeptic symptoms and its relationship to glycemic control and late complications. Dig Dis Sci. 2008;53:2646-9.

41. Rosenstock S, Kay L, Rosenstock C, Andersen LP, Bonnevie O, Jørgensen T. Relation between $H$. pylori infection and gastrointestinal symptoms and syndromes. Gut. 1997;41:169-176.

42. Perura DA. The report of the digestive health initiative SM international update conference on H. pylori. Gastroenterol. 1997;113:4-8.

43. Salih BA, Abasityanik MF, Saribasak H, Huten O,Sander EA. Follow-up study on the effect of $H$. pylori eradication on the severity of gastric histology. Dig Dis Sci. 2005;50(8):1517-1522

44. Kandulski $A$, Venerito $M$, Malfertheiner $P$. Therapeutic strategies for the treatment of dyspepsia. Expert Opin Pharmacother. 2010;11(15):2517-2525.

45. Shennak MM, Kilani AF. H. pylori in dyspeptic Jordanian patients. Trop Gastroenterol. 1998;19:15-18.

46. Britt DP, Barakat MH, Tungekar MF, Painchaud SM, Adlouni M, Kern K, et al. H. pylori in dyspeptic patients in Kuwait. J Clin Pathol. 1990;43:987-991.

47. Ibrahim BH, Anim JT, Sarkar C. H. pylori associated chronic gastritis in Kuwait. Ann Saudi Med. 1995;15:570-574.

48. Gunaid AA, Hassan NA, Murray-Lyon I. Prevalence and risk factors for H. pylori infection among Yemeni dyspeptic patients. Saudi Med J. 2003;24 512-517.

49. van der Hulst RMW, Tylgot GNJ. H. pylori and peptic ulcer disease. Scand J Gastroenterol. 1996;31(220):10-8.

50. Mustapha SM, Bolori N, Ajayi H, Nggada UH, Pindiga W, Gashau, et al. Endoscopic findings and the frequency of $H$. pylori among dyspeptic patients in North-Eastern Nigeria. Internet J Gastroenterol. 2007;6(1). DOI: 10.5580/2a4.

51. Lee MG, Emery H, Whittle D, Jackson D. H. pylori infection in patients with functional dyspepsia in Jamaica. Internet J Trop Med. 2009;5(2). DOI: 10.5580/3ad.

52. Holcombe C, Umar H, Lucas SB, Kaluba J. Low incidence of clinically significant gastroduodenal pathology despite high incidence of $H$. pylori infection. Trans $\mathrm{R}$ Soc Med Hyg. 1994;88:569-571.

53. Ndububa DA, Agbakwuru AE, Adebayo RA, Olasode BJ, Olaomi OO, Adeosun OA, et al. Upper Gl findings and incidence of $H$. pylori infection in Nigerian patients with dyspepsia. West Afr J Med. 2001;20(2):140-145. 
54. Bakka AS, Salih BA. Prevalence of $H$. pylori infection in asymptomatic subject in Libya. Diagn Microbiol Infect Dis. 2002;43:265-268.

55. Tijjani BM, Borodo MM, Samaila AA. H. pylori infection in dyspeptic patients at Kano, Nigeria. Borno Med J. 2005; 2:14-17.

56. Jemilohun AC, Otegbayo JA, Ola SO, Oluwasola OA, Akere A. Prevalence of H. pylori among Nigerian patients with dyspepsia in Ibadan. Pan Afr Med J. 2010;6:18.

57. Saadah Ol. H. pylori infection in Saudi children: clinical, endoscopic and pathological findings. Arab J Gastroenterol. 2010;11:39-43.

58. Maaroos HI, Kekki M, Villako K, Sipponen P, Tamm A, Sadeniemi L. The occurrence and extent of $H$. pylori colonisation and antral and body gastritis profiles in Estonian population sample. Scand J Gastroenterol. 1990;25:1010-1017.

59. Hashemi MR, Rahnavardi M, Bikdeli B, Dehghani Zahedani M. H. pylori infection among 1000 southern Iranian dyspeptic patients. World J Gastroenterol. 2006;12(34):5479-5482.

60. Tarkhashvili N, Beriashvili R, Chakvetadze N, Moistsrapishvili M, Chokheli M, Sikharulidze $\mathrm{M}$, et al. $\mathrm{H}$. pylori infection in patients undergoing upper endoscopy, Republic of Georgia. Emerg Infect Dis. 2009;15(3):504-505.

61. Al-Akwaa AM. Prevalence of $H$. pylori infection in agroup of morbidly obese Saudi patients undergoing bariatric surgery a preliminary report. Saudi J gastroenterol. 2010; 16(4):264-267.

62. Lopes J. H. pylori infection: update on diagnosis and management. JAAPA. 2010;23(7):20-37.

63. Machado AMD, Figueiredo C, Seruca R, Rasmussen LJ. H. pylori infection generates genetic instability in gastric cells. Biochim Biophys Acta. 2010;1806:58-65.

64. Blaser MJ. Hypothesis on the pathogenesis and natural history of $\mathrm{H}$. Pylori induced inflammation. Gastroenterol. 1992;102:720-727.

65. Mohammadi M, Talebkhan Y, Khalili G, Mahboudi1 F, Massarrat S, Zamaninia1 L, et al. Advantage of using a home-made elisa kit for detection of $H$. pylori infection over commercially imported kits. Indian J Med Microbiol. 2008;26(2):127-131.

66. Khan MA, Ghazi HO. H. pylori infection in asymptomatic subjects in Makkah, Saudi Arabia. J Pak Med Assoc. 2007;57:114-117.

67. Oluwasola AO, Ola SO, Saliu L, Sulanke TF. H. pylori infection in South Nigerians: a serological study of dyspeptic patients and healthy individuals. West Afr $\mathrm{J}$ Med. 2002;21:138-141.

68. Ben Ammar A, Cheikh I, Kchaou M, Ouergh H, Chaabourn H. Prevalence of $H$. pylori infection in normal or asymptomatic patients. Tunis Med. 2003;81(3):200-204.

69. Salem OE, Youssri AH, Mohammad ON. The prevalence of $H$. pylori antibodies in asymptomatic young egyptian persons. J Egypt Public Health Assoc. 1993;68(34):333-352.

70. Miwa H, Kikuchi S, Ohtaka K. Insufficient diagnostic accuracy of imported serological kits for $H$. pylori infection in Japanese population. Diagn Microbial Infect Dis. 2000;36:95-99.

71. Shirin H, Bruck R, Kenet G, Krepel Z, Wardi Y, Reif S, et al. Evaluation of a new immunochromatographic test for $H$. pylorilgG antibodies in elderly symptomatic patients. J Gastroenterol. 1999;34:7-10.

72. Talebkhan Y, Mohammadi M, Khalili G, Sheykholeslami A, Rakhshani N, Mahboudi F, et al. Detection of $H$. pylori infection by imported IgG ELISA kits in comparison with Iranian home made kit. Govaresh. 2006;11(2):120-125.

73. Monteiro LA, de Mascarel AM, Sarrasqueta B, Bergey C, Barberis P, Talby D. et al. Diagnosis of $H$. pylori infection: noninvasive methods compared to invasive methods and evaluation of two new tests. Am J Gastroenterol. 2001;96:353-358. 
74. Laheij RJ, Straatman H, Jansen JB, Verbeek AL. Evaluation of commercially available H. pylori serology kits: a review. J Clin Microbiol. 1998;36:2803-2809.

75. Logan RP, Walker MM. ABC of the upper gastrointestinal tract: epidemiology and diagnosis of $H$. pylori infection. BMJ. 2001;323:920-922.

76. Perez-Perez Gl, Taylor DN, Bodhidatta L, Wongsrichanalai J, Baze WB, Dunn BE, et al. Seroprevalence of $H$. pylori infections in Thailand. J Infect Dis. 1990;161:12371241.

77. Lin TT, Yeh CT, Yang E, Chen PC. Detection of $H$. pylori by polymerase chain reaction assay using gastric biopsy specimens taken for CLO test. J Gastroenterol. 1996;31:329-332.

78. Hanvivatvong O, Tatiyakavee K, Thong-Ngam D, Pongpanich A, Chirathaworn C, Suwanagool $\mathrm{P}$, et al. Detection of antibody in serum and secretion for the diagnosis of H. pylori infection. J Med Assoc Thai. 2002; 85(1): 383-388.

79. Hoshiya S, Tokunaga K, Tanaka A, Takahashi S. Serological diagnosis of H. pylori infection. Nippon Rinsho. 2001;59:259-264.

80. Leung WK, Chow TP, Ng EK, Chan FK, Chung SC, Sung JJ. Validation of a new immunoblot assay for the diagnosis of $H$. pylori. Aliment Pharmacol Ther. 2001;15:423-428.

81. Mohammadi M. Genotype and strains of Iranian H. pylori strains based on PCR-RFLP of conserved and non-conserved genes. Bull Soc Pathol Exot. 2000;93:224-226.

82. Mohammadi M, Oghalaie A, Mohajerani N, Massarrat S, Nasiri M, Bennedsen M, et al. Prevalence of $H$. pylori vacuolatingcytotoxin and its allelic mosaicism as a predictive marker for Iranian dyspeptic patients. Bull Soc Pathol Exot. 2003;96:3-5.

83. Bodhidatta L, Hoge CW, Churnratanakul S, Nirdnoy W, Sampathanukul P, Tungtaem C, et al. Diagnosis of $H$. pylori infection in a developing country: comparison of two ELISAs and a seroprevalence study. J Infect Dis. 1993;168(6):1549-1553.

(c) 2013 Abo-Shadi et al.; This is an Open Access article distributed under the terms of the Creative Commons Attribution License (http://creativecommons.org/licenses/by/3.0), which permits unrestricted use, distribution, and reproduction in any medium, provided the original work is properly cited.

Peer-review history:

The peer review history for this paper can be accessed here: http://www.sciencedomain.org/review-history.php?iid=205\&id=12\&aid=1141 